\title{
Occupational stress and burnout among Hong Kong dentists
}

\author{
HB Choy, May CM Wong *
}

\section{A B S T R A C T}

Introduction: Professional burnout has been described as a gradual erosion of a person and may be one of the possible consequences of chronic occupational stress. Although occupational stress has been surveyed among dentists in Hong Kong, no study has been published about burnout in the profession. This study aimed to evaluate burnout among Hong Kong dentists and its association with occupational stress.

Methods: We surveyed a random sample of 1086 registered dentists in Hong Kong, which formed $50 \%$ of the local profession. They were mailed an anonymous questionnaire about burnout and occupational stress in 2015. The questionnaire assessed occupational stress, coping strategies, effects of stress, level of burnout, and sociodemographic characteristics of the respondents. Occupational stress assessment concerned 33 stressors in five groups: patient-related, time-related, income-related, job-related, and staff-/technically related. Level of burnout was assessed by the Maslach Burnout Inventory-Human Services Survey (22 items) with three scores: emotional exhaustion, depersonalisation, and personal accomplishment.

Results: Completed questionnaires were received from 301 dentists (response rate, 28.3\%), of whom $25.4 \%$ had a high level of emotional exhaustion, $17.2 \%$ had a high level of depersonalisation, and
$39.0 \%$ had a low level of personal accomplishment. Only $7.0 \%$ of respondents, however, had a high level of overall burnout (high emotional exhaustion, high depersonalisation, and low personal accomplishment). A high level of overall burnout was significantly associated with a higher mean score for job-related stressors and lack of postgraduate qualifications $(\mathrm{P}<0.05)$.

Conclusions: Patient-related stressors are the top occupational stressors experienced by dentists in Hong Kong. In spite of this, a low proportion of dentists have a high level of overall burnout. There was a positive association between occupational stress and level of burnout.

\author{
Hong Kong Med J 2017;23:480-8 \\ DOI: $10.12809 / \mathrm{hkmj} 166143$ \\ 1 HB Choy, MGD (CDSHK), MRACDS (GDP) \\ ${ }^{2}$ MCM Wong *, MPhil, PhD \\ Dentistry and Maxillofacial Surgery, Caritas Medical Centre, \\ Shamshuipo, Hong Kong \\ Faculty of Dentistry, The University of Hong Kong, Pokfulam, Hong Kong \\ * Corresponding author: mcmwong@hku.hk
}

An earlier version of this paper was presented at the 94th General Session \& Exhibition of the IADR, 3rd Meeting of the IADR Asia Pacific Region and 35th Annual Meeting of the IADR Korean Division held in Seoul, Korea on 22-25 June 2016.

New knowledge added by this study

- Approximately 7.0\% of Hong Kong dentists have a high level of overall burnout.

- Job-related stressors and postgraduate qualifications are associated with a high level of overall burnout.

Implications for clinical practice or policy

- Although only a low proportion of Hong Kong dentists has high overall burnout, this issue should not be overlooked. Dentistry is quite a lonely profession. Peer support and sharing is important for the development of dentistry in Hong Kong.

- Dentists are advised to update their knowledge and skills to meet the increasing expectations and challenges from patients and the society.

\section{Introduction}

Professional burnout can be one of the possible consequences of chronic occupational stress. ${ }^{1}$ Burnout has been described as a gradual erosion of the person and comprises three characteristics. ${ }^{2}$ First, the individuals are exhausted, either mentally or emotionally. ${ }^{2}$ They feel drained, tired with insufficient energy, and are unable to cope. ${ }^{3}$ Second, they may have a negative, indifferent, or cynical attitude towards patients, clients, or colleagues. ${ }^{2}$ They feel numb about work and distance themselves emotionally. ${ }^{3}$ Finally, they also tend to feel dissatisfied with their own performance and evaluate themselves negatively. ${ }^{2}$ They find difficulty in concentrating on their work and caring about their families. ${ }^{3}$ The consequences of burnout can be very serious. Maslach and Jackson ${ }^{4}$ found that the quality of care and service provided by individuals 
who have burnout syndrome may be substandard. Burnout has also been found to be associated with job turnover, absenteeism, low morale, and personal dysfunction. $^{3}$ Maslach and her colleague ${ }^{5,6}$ have studied the burnout syndrome for many years and devised a measurement tool-the Maslach Burnout Inventory-Human Services Survey (MBI-HSS)., Although some studies of burnout have been conducted among dentists using the MBI-HSS, ${ }^{1,8-10}$ most studies on stress and burnout in health professions have focused on physicians ${ }^{11-13}$ and nurses. ${ }^{14,15}$

In 2001, a survey was conducted to investigate the sources of occupation stress among dentists in Hong Kong. ${ }^{16}$ There has been no published study on burnout among dentists in Hong Kong since then. We conducted a cross-sectional study to investigate the burnout among dentists in Hong Kong and the association between occupational stress and burnout. The objectives of our study were to identify the occupational stressors and the prevalence of burnout among dentists in Hong Kong and their association.

\section{Methods}

\section{Survey design and sample}

In October 2015, there were 2173 locally registered dentists working in Hong Kong according to the Dental Council of Hong Kong. ${ }^{17}$ In order to achieve the width of the $95 \%$ confidence interval (CI) calculated from the sample proportion estimates of burnout outcomes no wider than $\pm 5 \%$, a sample of 384 dentists was needed (using a conservative assumption of sample proportions to be $50 \%$ ). Taking into account the low response rate $(<40 \%)$ achieved by previous surveys in Hong Kong, $50 \%$ of the dentists were systematically randomly sampled (with a random start of ' 2 ' generated from Excel) from the published list of registered dentists according to their family names and a sample size of 1086 was chosen. The questionnaires were mailed in sealed envelopes in early November 2015 along with a stamped, self-addressed envelope. The participants were assured of confidentiality. No names and addresses were asked for and no codes were marked on the questionnaires or return envelopes. Questionnaires for selected government dentists were sent collectively to the Department of Health and delivered internally. Reminders were sent to all selected private dentists in late November or early December 2015. Participants did not receive any specific incentive to complete this survey.

\section{Construction of questionnaire}

The questionnaire assessed the sources of occupational stress, stress-coping strategies, effects of stress on work, level of burnout, and socio-

\section{香港牙醫的職業壓力和過度勞累的情況} 蔡鴻涁、王春美

引言：工作上過度勞累被認為會漸漸侵蝕個人身心健康, 亦可能是長 期職業壓力的其中一種後果。以往曾經對香港牙醫的職業壓力進行調 查, 可惜並無有關他們過度勞累的研究報告。本研究旨在評估香港牙 醫過度勞累的情況以及與職業壓力的關係。

方法: 我們隨機抽樣並把有關過度勞累與職業壓力的匿名調查問卷寄 給1086名香港註冊牙醫, 抽樣對象佔本地牙醫數目的一半。問卷評估 受訪者的職業壓力、應對策略、壓力造成的影響、過度勞累的程度以 及搜集受訪者的人口特徵。職業壓力評估涉及33項壓力來源, 它們分 別與以下五方面相關：病人、時間、收入、工作以及同事 / 技術性。 按Maslach Burnout Inventory-Human Services Survey（22項），過 度勞累主要表現在三方面：情緒耗竭、去人性化和個人成就。本研究 找出受訪者這三方面的分數。

結果：共分析了 301 份問卷, 回應率為 $28.3 \%$ 。受訪者中 $25.4 \%$ 的情緒 耗竭程度較高, $17.2 \%$ 的去人性化程度較高, $39.0 \%$ 的個人成就感低 落。雖然如此, 總體上只有 $7.0 \%$ 受訪者的過度勞累情況較為嚴重（即 有較高程度的情緒耗竭和去人性化, 以及較低的個人成就感）。嚴重 的過度勞累與以下兩方面明顯相關: 來自職業本身的壓力因素和欠缺 研究生學歷 $(\mathrm{P}<0.05)$

結論 : 香港牙醫遇到最主要的職業壓力因素均與患者相關。儘管如 此, 只有較低比率的牙醫過度勞累的情況較為嚴重。職業壓力與過度 勞累程度呈正相關。

demographic characteristics of the study subjects. There were 33 occupational stressors for identifying the sources of stress; 26 of which were proposed by Cooper et al. ${ }^{18}$ An additional seven stressors were proposed by Waddington. ${ }^{19}$ Participants were asked to rate the level of stress they experienced on a 5 -point scale ranging from ' $1=$ No stress' to ' $5=\mathrm{A}$ great deal of stress'. The 33 stressors were grouped into five domains: patient-related, time-related, income-related, job-related, and staff-related or technically related (Box). Based on the work by Cooper et al, ${ }^{18} 10$ stress-coping strategies of dentists were included. Participants were asked how often they would use these stress-coping strategies with responses categorised on a 5-point scale ranging from ' 1 = Never' to ' 5 = Always' (Box). Based on the work of Kopec and Esdaile, ${ }^{20}$ five effects of occupational stress on work were included with responses rated on a 4-point scale ranging from ' $1=$ Not at all' to ' $4=$ A lot' (Box). Of note, MBI-HSS, ${ }^{7}$ which has been recognised as the leading measure of burnout, was also included and consisted of 22 items with responses rated on a 7-point scale ranging from ' $0=$ Never' to ' 6 = Every day'. The MBI-HSS addressed three general scales: emotional exhaustion (EE; 9 items with score range of 0-54) measuring the feelings of being emotionally overextended and exhausted by one's work; depersonalisation (DP; 5 items with 
BOX. Occupational stressors, coping strategies, and effects of occupational stress on work

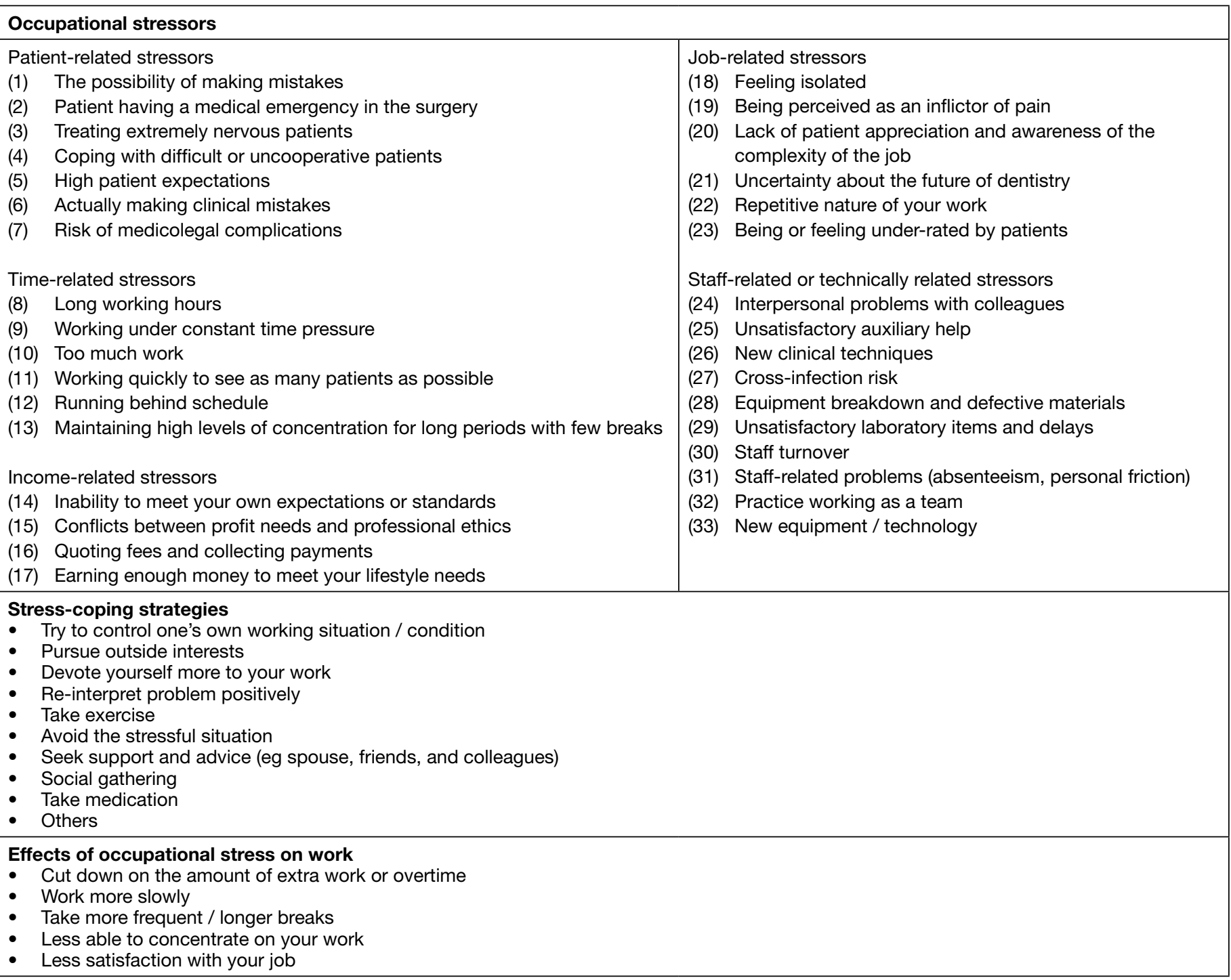

score range of 0-30) measuring the unfeeling and impersonal response towards recipients of one's service, care treatment, or instruction; and personal accomplishment (PA; 8 items with score range of 0-48) measuring the feelings of competence and successful achievement in one's work. Personal information about the participants was also collected and included their age, gender, years of practice, type of practice, location, hours of work per week, marital status, working status of spouse, number of children, religious beliefs, whether the participant had postgraduate qualifications, and whether the participant was a specialist.

The Institutional Review Board of The University of Hong Kong/Hospital Authority Hong Kong West Cluster (HKU/HA HKW IRB, reference number: UW 15-524) approved the study prior to distribution of the questionnaires.

\section{Statistical analysis}

The mean score for each stressor group was calculated and ranked. Three subscale scores of MBI-HSS (EE, DP, and PA) were calculated and subjects categorised into one of the three groups - high, moderate, or low level of burnout. Those with EE score of $\geq 27$ were considered to have high EE level, 17-26 moderate and 0-16 low level. Those with DP score of $\geq 13$ were considered to have high DP level, 7-12 moderate and 0-6 low level. Those with PA score of $\leq 31$ were considered to have low PA level, 32-38 moderate and $\geq 39$ high level. Subjects with high EE, high DP, and low PA levels simultaneously were considered to have a high level of overall burnout. Others were considered to have low overall burnout. Of the results, 95\% CIs were computed as well.

The relationships between EE, DP and PA scores, and the set of 17 independent variables (12 
demographic variables and the five stressor group scores) were analysed by analysis of covariance (ANCOVA). A forward selection method was adopted. In this approach, independent variables were added into the model one at a time. In each step, each variable that was not already in the model was tested for inclusion in the model. The most significant of these variables was added to the model. Finally, only significant variables were selected in the final model.

The relationship between levels of overall burnout (high and low) and the set of 17 independent variables was analysed by multiple logistic regression. A forward selection method was adopted as well. All analyses were performed using the SPSS (Windows version 22.0; IBM Corp, Armonk [NY], US) and the level of significance was set at 0.05 .

\section{Results}

\section{Response}

A total of 1086 questionnaires were sent to the randomly selected dentists. Reminders were sent to the selected private dentists 2 to 4 weeks later. We received 301 completed questionnaires and 22 questionnaires returned undelivered by the post office, resulting in a response rate of $28.3 \%$ (301/ [1086-22] x 100\%).

\section{Demographics}

The demographics of the respondents are shown in Table 1. Approximately $65 \%$ of the respondents were male and $79 \%$ worked in the private sector that also included non-governmental organisations. Approximately $46 \%$ of dentists had acquired one or more postgraduate qualifications. More than $86 \%$ of the respondents were general dental practitioners. Over a quarter (29\%) had never married and more than half (54\%) claimed to have no religious beliefs.

\section{Occupational stress}

The top 10 stressors according to the percentage distribution of the respondents' ratings ' 4 ' or ' 5 ' (considered to be high level) are shown in Figure 1. Six of the top 10 highest ranked stressors (and actually the top five highest ranked) were patientrelated stressors and three of the 10 highest ranked stressors were time-related. The patient-related stressors group had the highest mean ( \pm standard deviation [SD]) score $(3.4 \pm 0.8)$, followed by the time-related stressors group $(3.1 \pm 0.8)$, staff-related or technically related stressors group $(2.6 \pm 0.6)$, income-related stressors group $(2.5 \pm 0.7)$, and jobrelated stressors group $(2.5 \pm 0.7)$. Female dentists had a higher mean score than male dentists for patient-related, job-related, and staff-/technically related stressors (3.5 vs 3.3, 2.6 vs 2.4 , and 2.7 vs 2.5 , respectively; all $\mathrm{P}<0.05)$. Dentists with more than
TABLE I. Demographics of the respondents

\begin{tabular}{lc}
\hline Demographics & $\begin{array}{c}\text { No. (\%) of } \\
\text { respondents }\end{array}$ \\
\hline $\begin{array}{l}\text { Gender }(n=299) \\
\text { Male }\end{array}$ & $195(65.2)$ \\
$\quad$ Female & $104(34.8)$ \\
Age (years) $[n=298]$ & \\
$\quad \leq 44$ & $159(53.4)$ \\
$\quad \geq 45$ & $139(46.6)$ \\
Years of practice $(n=300)$ & \\
$<20$ & $163(54.3)$ \\
$\geq 20$ & $137(45.7)$
\end{tabular}

Type of practice $(n=300)$

$\begin{array}{lr}\text { Public } & 63(21.0) \\ \text { Private } & 237(79.0)\end{array}$

Location of practice (for private practice only) $[n=233]$

$\begin{array}{lr}\text { Commercial area } & 102(43.8) \\ \text { Residential area } & 79(33.9) \\ \text { Both } & 52(22.3)\end{array}$

Postgraduate qualifications $(n=299)$

Yes

137 (45.8)

No

162 (54.2)

Specialist status $(n=297)$

$\begin{array}{lr}\text { General dental practitioners } & 256(86.2) \\ \text { Specialists } & 41(13.8)\end{array}$

No. of working hours per week $(n=298)$

$<60$

$\geq 60$ $20(6.7)$

Marital status $(\mathrm{n}=298)$

Never married 85 (28.5)

Married

Working status of spouse $(n=210)$

Not working 71 (33.8)

Working 139 (66.2)

Number of children $(n=213)$

No children 52 (24.4)

Have children

$161(75.6)$

Religion $(\mathrm{n}=300)$

No religious belief

$162(54.0)$

Has religious belief 138 (46.0)

20 years of practice (3.3), who held postgraduate qualifications (3.2), or who had completed specialist training (3.0) had a lower mean score for patientrelated stressors than those with less than 20 years of practice (3.4, 3.5, and 3.4 respectively; all $\mathrm{P}<0.05$ ).

\section{Stress-coping strategies}

The highest ranked strategy (with ratings '4' or ' 5 ') 


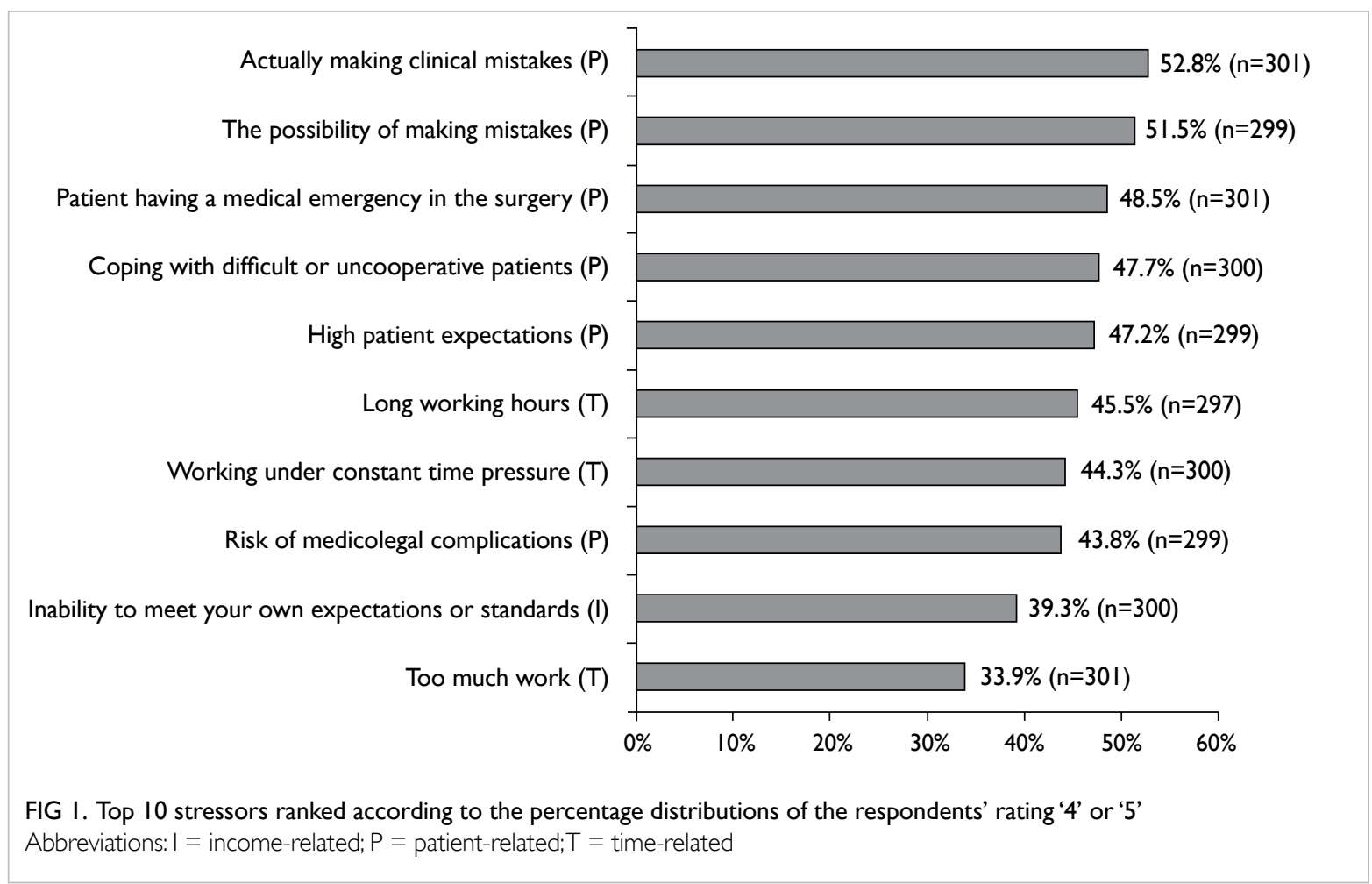

to cope with occupational stress was 'try to control one's own working situation / condition' (59.0\%), followed by 'pursue outside interests' (58.6\%), 'avoid the stressful situation' (51.7\%), and 'take exercise' $(51.0 \%)$. Other less-commonly used strategies $(<50 \%)$ were 're-interpret problem positively', 'seek support and advice', 'social gathering,' 'devote yourself more to your work,' 'take medication,' and 'others'.

\section{Effects of occupational stress on work}

The highest ranked effect (with ratings ' 3 ' or ' 4 ') of occupational stress on work was to 'cut down on the amount of extra work or overtime' (41.7\%) and 'take more frequent / longer breaks' (30.7\%). Fewer than $30 \%$ of respondents reported 'less satisfaction with your job', 'work more slowly', and 'less able to concentrate on your work' as the effects of occupational stress on work.

\section{Maslach Burnout Inventory-Human Services Survey and level of burnout}

The mean $( \pm \mathrm{SD})$ score for EE, DP and PA and the level of burnout are shown in Figure 2. Approximately a quarter of the respondents had a high EE level (25.4\%; 95\% CI, 20.5\%-30.3\%) while $17.2 \%$ (95\% CI, $12.9 \%-21.5 \%)$ and $39.0 \%$ (95\% CI, 33.5\%-44.5\%) had high DP and low PA level, respectively. Nonetheless only $7.0 \%$ (95\% CI, 4.1\%-9.9\%) of respondents had a high level of overall burnout (ie high EE, high DP, and low PA).

\section{Maslach Burnout Inventory-Human Services Survey, occupational stress, and demographic variables}

The relationship between EE, DP and PA scores, five stressor groups, and the 12 demographic variables was analysed by ANCOVA. The final models are

\begin{tabular}{|c|c|c|c|}
\hline \multirow{2}{*}{$\begin{array}{r}100 \\
90\end{array}$} & 口Low & $\square$ Moderate & $\square$ High \\
\hline & \multirow{4}{*}{$44.8 \%$} & \multirow{4}{*}{$44.8 \%$} & \multirow{3}{*}{$32.2 \%$} \\
\hline 80 & & & \\
\hline 70 & & & \\
\hline 60 & & & \multirow{2}{*}{$28.8 \%$} \\
\hline$\%^{50}$ & \multirow[b]{2}{*}{$29.8 \%$} & \multirow{3}{*}{$38.0 \%$} & \\
\hline & & & \multirow{3}{*}{$39.0 \%$} \\
\hline 20 & \multirow[b]{2}{*}{$25.4 \%$} & & \\
\hline \multirow[t]{2}{*}{10} & & $17.2 \%$ & \\
\hline & EE & DP & PA \\
\hline \multicolumn{2}{|c|}{ Mean \pm SD $19.4 \pm 11.3$} & $7.8 \pm 5.2$ & $33.3 \pm 8.4$ \\
\hline \multicolumn{4}{|c|}{$\begin{array}{l}\text { FIG 2. Level of burnout (low PA indicates high level of } \\
\text { burnout) } \\
\text { Only 7.0\% had a high level of overall burnout (high EE, high DP, } \\
\text { and lower PA) } \\
\text { Abbreviations: DP = depersonalisation; EE = emotional } \\
\text { exhaustion; PA = personal accomplishment; SD = standard } \\
\text { deviation }\end{array}$} \\
\hline
\end{tabular}


shown in Table 2. For EE, among the 17 independent variables investigated, only three significant variables $(\mathrm{P}<0.05)$ were selected in the final model. The dentists whose spouses were not working had a higher mean EE score by 4.15 compared with those whose spouses were working $(\mathrm{P}=0.024)$. Those with higher scores in the time-related stressors group had higher EE scores. For every one unit increase in time-related stressors group score, the mean EE score increased by $4.51(\mathrm{P}<0.001)$. Finally, those with higher scores in the job-related stressors group also had higher EE scores; for every one unit increase in job-related stressors group score, the mean EE score increased by $4.54(\mathrm{P}<0.001)$. For $\mathrm{DP}$, only two significant variables $(\mathrm{P}<0.05)$ were selected in the final model. Private dentists who worked in residential areas had higher mean DP scores by 2.51 compared with those private dentists who worked in commercial areas $(\mathrm{P}=0.005)$. Also, those with higher scores in the job-related stressors group also had higher DP scores; for every one unit increase in job-related stressors group score, the mean DP score increased by $2.35(\mathrm{P}<0.001)$. For PA, only one significant variable $(\mathrm{P}<0.05)$ was selected in the final model. Those with higher scores in income-related stressors group were found to have lower PA scores. For every one unit increase in job-related stressors group score, the mean PA score decreased by 3.40 $(\mathrm{P}<0.001)$.

\section{Level of burnout, occupational stress, and demographic variables}

The relationships between levels of overall burnout (high and low), five stressors groups, and the

TABLE 2. Relationship between emotional exhaustion, depersonalisation and personal accomplishment scores, and the significant independent variables

\begin{tabular}{|c|c|c|c|c|}
\hline Independent variables & Estimate & Standard error & $P$ value & Multiple comparison \\
\hline \multicolumn{5}{|l|}{ Emotional exhaustion } \\
\hline Spouse working status & & & 0.024 & (2) $>$ (3) \\
\hline Unmarried (1) & 1.62 & 1.30 & & \\
\hline Not working (2) & 4.15 & 1.53 & & \\
\hline Working* ${ }^{*}(3)$ & - & - & & \\
\hline Time-related stressors & 4.51 & 0.92 & $<0.001$ & \\
\hline Job-related stressors & 4.54 & 1.01 & $<0.001$ & \\
\hline (Intercept) & -6.82 & 2.45 & 0.006 & \\
\hline \multicolumn{5}{|l|}{ Depersonalisation } \\
\hline Location of practice & & & 0.005 & (3) > (2) \\
\hline Public sector dentists (1) & -1.05 & 0.92 & & \\
\hline Commercial area (2) & -2.01 & 0.84 & & \\
\hline Residential area (3) & 0.50 & 0.87 & & \\
\hline \multicolumn{5}{|l|}{ 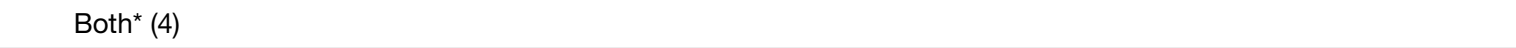 } \\
\hline Job-related stressors & 2.35 & 0.39 & $<0.001$ & \\
\hline (Intercept) & 2.77 & 1.18 & 0.019 & \\
\hline \multicolumn{5}{|l|}{ Personal accomplishment } \\
\hline Income-related stressors & -3.40 & 0.65 & $<0.001$ & \\
\hline (Intercept) & 41.81 & 1.71 & $<0.001$ & \\
\hline
\end{tabular}

* Reference group

TABLE 3. Relationship between levels of overall burnout and the significant independent variables

\begin{tabular}{lccc}
\hline Independent variables & Odds ratio & 95\% Confidence interval & P value \\
\hline Postgraduate qualifications & & & 0.038 \\
\hline No & 5.08 & $1.09-23.61$ & \\
Yes $^{*}$ & 1.00 & & \\
\hline Job-related stressors & 3.74 & $1.77-7.87$ & 0.001 \\
\hline
\end{tabular}

* Reference group 
demographic variables were analysed by multiple logistic regression. The results are shown in Table 3; only two significant variables $(\mathrm{P}<0.05)$ were selected. The chance of having a high level of overall burnout among dentists with no postgraduate qualifications was 5.08 times higher $(95 \% \mathrm{CI}, 1.09-23.61)$ than those with postgraduate qualifications $(\mathrm{P}=0.038)$. Also, for every one unit increase in job-related stressors group score, the odds of having a high level of overall burnout was 3.74 times as likely $(95 \% \mathrm{CI}$, 1.77-7.87; $\mathrm{P}=0.001)$.

\section{Discussion}

This survey revealed that the highest ranked stressors were patient-related. Several stress-coping strategies and effects of occupational stress on work were identified. Only $7 \%$ of dentists had a high level of overall burnout. Dentists without postgraduate qualifications and higher job-related stressor scores were more likely to have a high level of overall burnout.

\section{Occupational stress and coping strategies}

Comparison of these results with those of a previous study published in $2001^{16}$ reveals that the situation in Hong Kong has changed little over 15 years. In both surveys, six of the top 10 stressors were patientrelated, three were time-related, and one was incomerelated. There was, however, an increase in the percentage distributions of the stressors, indicating an increased stress level for dentists in Hong Kong in the past decade. This may be related to increasing demands and expectations of patients. Patients can now find much information on the internet and ask many questions based on the information they may find. This is a novel challenge for dentists. Moreover, the property rents in Hong Kong have increased much over the last 10 years with a consequent increase in the overhead costs of running a dental clinic. As a result, dentists need to work harder and see more patients to generate sufficient income to cover their costs.

Female dentists had higher mean scores than male dentists for patient-related, job-related, and staff-/technically related stressors. This may be because they are taking care of their own family as well as working as a dentist. Dentists with more experience, higher postgraduate qualifications, and specialist training had lower mean scores in the patient-related stressors group. This may imply that dentists with more competent skills and knowledge were less stressed.

In the current and $2001^{16}$ studies, the most prevalent method of coping with stress was 'try to control one's own working situation / condition'. Most dentists worked on their own and were selfreliant, even when they were facing stress.

\section{Maslach Burnout Inventory-Human Services Survey and level of burnout}

Higher EE score was significantly associated with those dentists whose spouses were not working and those with higher mean scores in time-related and job-related stressors groups. The financial pressure on a dentist may be lessened if the spouse works and this may have contributed to the lower EE score. Higher DP score was significantly associated with working in a residential area and higher mean score in job-related stressors group. This may be due to differing patient profiles in residential areas. Those who seek dental care from dentists in residential areas may be less educated, and less willing or less able to pay for dental treatment. Thus, the dentists have to spend more time with each patient but accrue less income with a consequent higher DP score. Lower PA score was significantly associated with those dentists with lower mean score in income-related stressors group. One of the rewards for a dentist is to earn a living by providing a professional dental service. If a dentist has difficulty in earning, he may have a lower sense of PA.

A high level of overall burnout was significantly associated with a higher mean score in job-related stressors group and no postgraduate qualifications. Those with postgraduate qualifications may have better knowledge, technique, and communication skills to deal with patients. This may have contributed to lower overall burnout.

The mean scores of the three subscales (EE, DP, and PA) of MBI of studies in Korea, ${ }^{8}$ Northern Ireland, ${ }^{9} \mathrm{UK},{ }^{10}$ Dutch, $^{21}$ and Hong Kong doctors ${ }^{11}$ are shown in Figure 3 for comparison. Generally speaking, the mean scores of EE and DP of dentists in Hong Kong were lower than those in other countries while mean PA score was in between. It is possible that Hong Kong dentists can tolerate stress better. In Hong Kong, the competition to study dentistry is very strong. A secondary school student must perform very well in public examinations to be admitted to the only dental school in Hong Kong. Locally trained students are used to this kind of keen competition. In Hong Kong, lower mean EE and DP scores and higher mean PA scores among dentists suggest that they are not as stressful as medical doctors. This may be due to the different nature of their jobs. Most dentists in Hong Kong practise in the private sector and seldom need to be on-call. In comparison, a lot of Hong Kong medical doctors work in public hospitals and need to be on-call. Moreover, the public have high expectations of the public health care service and this may contribute to the higher level of burnout among Hong Kong doctors.

The level of burnout of the current study was compared with that reported in Korea ${ }^{8}$ and the UK. ${ }^{10}$ The percentage distribution of high EE (Hong Kong 


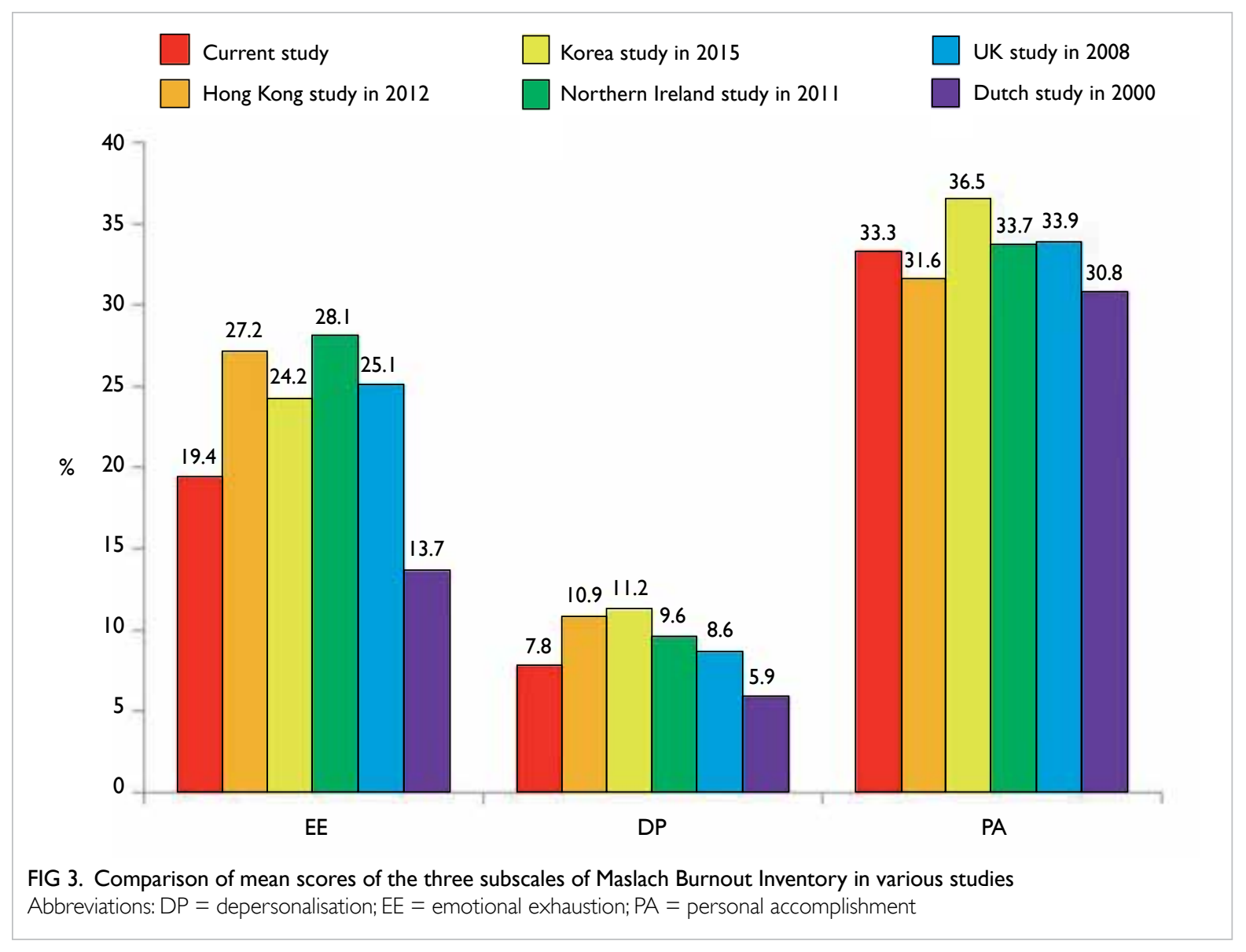

25.4\%, Korea 41.2\%, and UK 42.2\%) and DP (Hong Kong $17.2 \%$, Korea $55.9 \%$, and UK $19.5 \%$ ) level of Hong Kong dentists was lower compared with that of Korean and UK dentists. Hong Kong dentists, however, felt a lower sense of PA as reflected by the higher percentage of low PA (Hong Kong 39.0\%, Korea $31.5 \%$, and UK 31.9\%). This suggests that the dentists in Hong Kong had lower job satisfaction. Although the level of overall burnout of Hong Kong dentists was less than that in other countries, this issue should not be overlooked. Dentistry is quite a lonely profession that requires an individual to work alone most of the time. Peer support and sharing is important for the development of dentistry in Hong Kong.

\section{Limitations of the study}

The response rate of the current study was low $(<30 \%)$ although it was similar to other studies of health care professionals in Hong Kong. The selected dentists might be very busy and might not have time to complete the questionnaires. Others might not have been interested. Those dentists with a high level of burnout might have felt the questions too sensitive and thus been unwilling to participate. For those who participated, as stress and burnout were self-reported, there might have been information bias because of social desirability and thus our results might underestimate the level of stress and burnout among dentists in Hong Kong. As in all cross-sectional surveys, a causal relationship could not be established. With the small sample size, there was a possible lack of statistical power for the multiple logistic regression as evidenced by the wide $95 \% \mathrm{CI}$ of the odds ratio. In order to increase the response rate of future surveys, we may consider phoning each selected dentist to check if they have received the questionnaires and to invite them to participate. We may also consider using the internet for data collection.

\section{Recommendation}

Dentists with a higher stress level may consider working less to relieve pressure: approximately one quarter of dentists worked more than 50 hours a week, which contributed to the time-related stress. Dentists are advised to update their knowledge and skills to equip them for the increasing expectations and challenges from patients and society.

\section{Conclusion}

Patient-related stressors are the top occupational 
stressors experienced by dentists in Hong Kong. Nonetheless a small proportion of dentists have high overall burnout. There was a positive association between occupational stress and level of burnout.

\section{Acknowledgements}

We would like to thank the staff of the Faculty of Dentistry, The University of Hong Kong for their assistance in this study. We would also like to thank all the dentists who participated in the survey.

\section{Declaration}

All authors have disclosed no conflicts of interest.

\section{References}

1. Gorter RC, Albrecht G, Hoogstraten J, Eijkman MA. Work place characteristics, work stress and burnout among Dutch dentists. Eur J Oral Sci 1998;106:999-1005.

2. Rada RE, Johnson-Leong C. Stress, burnout, anxiety and depression among dentists. J Am Dent Assoc 2004;135:78894.

3. US National Library of Medicine. Depression: what is burnout? Available from: https://www.ncbi.nlm.nih.gov/ pubmedhealth/PMH0072470/. Accessed 15 Mar 2017.

4. Maslach C, Jackson SE. Maslach burnout inventory manual. Mountain View, CA: Consulting Psychologists Press; 1981.

5. Maslach C. Burned-out. Can J Psychiatr Nurs 1979;20:5-9.

6. Maslach C, Jackson SE. The measurement of experienced burnout. J Organ Behav 1981;2:99-113.

7. Maslach C, Jackson SE. Maslach burnout inventory manual. 2nd ed. Mountain View, CA: Consulting Psychologists Press; 1986.

8. Jin MU, Jeong SH, Kim EK, Choi YH, Song KB. Burnout and its related factors in Korean dentists. Int Dent I 2015;65:22-31.

9. Gorter RC, Freeman R. Burnout and engagement in relation with job demands and resources among dental staff in Northern Ireland. Community Dent Oral Epidemiol 2011;39:87-95.

10. Denton DA, Newton JT, Bower EJ. Occupational burnout and work engagement: a national survey of dentists in the United Kingdom. Br Dent J 2008;205:E13;discussion 3823.

11. Siu C, Yuen SK, Cheung A. Burnout among public doctors in Hong Kong: cross-sectional survey. Hong Kong Med J 2012;18:186-92.

12. Doolittle BR, Windish DM. Correlation of burnout syndrome with specific coping strategies, behaviors, and spiritual attitudes among interns at Yale University, New Haven, USA. J Educ Eval Health Prof 2015;12:41.

13. Jin WM, Zhang Y, Wang XP. Job burnout and organizational justice among medical interns in Shanghai, People's Republic of China. Adv Med Educ Pract 2015;6:539-44.

14. Portero de la Cruz S, Vaquero Abellán M. Professional burnout, stress and job satisfaction of nursing staff at a university hospital. Rev Lat Am Enfermagem 2015;23:54352.

15. Singh C, Cross W, Jackson D. Staff burnout-a comparative study of metropolitan and rural mental health nurses within Australia. Issues Ment Health Nurs 2015;36:528-37.

16. Wong MC, Ng KK, Tang AK, Tang GC, Lam VN. Occupational stress among dental practitioners in Hong Kong. Hong Kong Dent Assoc Millennium Rep 2001;II:505.

17. The Dental Council of Hong Kong. List of registered dentists under the General Register. Available from: http:// www.dchk.org.hk/en/list/index.htm. Accessed 22 Oct 2015.

18. Cooper CL, Watts J, Kelly M. Job satisfaction, mental health, and job stressors among general dental practitioners in the UK. Br Dent J 1987;162:77-81.

19. Waddington TJ. New stressors for GDPs in the past 10 years. Br Dent J 1997;182:82-3.

20. Kopec JA, Esdaile JM. Occupational role performance in persons with back pain. Disabil Rehabil 1998;20:373-9.

21. Gorter RC, Eijkman MA, Hoogstraten J. Burnout and health among Dutch dentists. Eur J Oral Sci 2000;108:2617. 